\title{
A Grid-connected Hybrid Renewable Energy System Using High-frequency Multi-winding Transformer and Phase Shift Modulation Technique
}

\author{
Ramesh Kumar ${ }^{1}$, Ravi Chandra ${ }^{2}$, Anand Kumar ${ }^{3}$ \\ 1,2,3 Power Electronics Research and Development Group, Power Systems Technology Pty Ltd, India
}

\begin{tabular}{l} 
Article Info \\
\hline Article history: \\
Received May 25, 2019 \\
Revised May 2, 2021 \\
Accepted May 4, 2021 \\
\hline
\end{tabular}

\section{Keywords:}

Multi-port Converter

Phase-shift Control

High-frequency Transformer

PV System

Wind Turbine Generator

Battery

\begin{abstract}
This paper presents a topology of multi-port phase-shift converter for integration of a PV system, a wind-turbine generator and a battery to supply a grid-connected domestic load. The main advantage of the topology is using a multi-winding high-frequency transformer to couple the input and outputs of the system. This simplifies the power flow control and provides isolation between the converter ports. Detailed operation of the proposed topology and the control system analysis are discussed. A numerical simulation of the proposed system is carried out to confirm the system operation and control technique.
\end{abstract}

Copyright $@ 2019$ Institute of Advanced Engineering and Science. All rights reserved.

\section{Corresponding Author:}

Ramesh Kumar,

Power Electronics Research and Development Group,

Power Systems Technology Pty Ltd, India

Email: Rameshzkumar1985@gmail.com

\section{INTRODUCTION}

Multiport converters, have been an attractive research topic over the past decade due to their application in integration of several renewable energy sources into a single power processing unit. Therefore, a large number of multi-port converter topologies has been introduced in the literature so far [1]-[9]. The proposed topologies can be classified as the topologies operate based on the series or parallel connection of small conversion cells [10], time-sharing concept [11]-[13] and magnetic flux additivity [14]. Furthermore, some of them have the property of bidirectional power flow between the connected ports, while others are unidirectional only [15]. Among the proposed topologies, those are based on a magnetic-coupling through a multi-winding transformer have attracted more attention due to their excellent features in terms of flexibility, safety and isolation and operational power range. This provides an isolation between the ports and facilitate connecting several sources having substantially different operating voltages thanks to the transformer turns ratio [16]. On the other hand, a simpler power flow control can be achieved by using a phase-shift control technique [17]-[19]. A complete study on the magnetically coupled multi-port converters have been presented in [16]-[20]. It should be noted that the system operation and design of multi-winding high-frequency transformer become very complex in the case of large number windings [21]-[24]. A magnetically coupled converter with two input and one output is presented in [25] where instead of combining input dc sources in electric form, they are combined in magnetic form by adding up the produced magnetic fluxes together using the magnetic core of the multiwinding transformer. The power flow in the proposed converter has been drawn from two different dc sources and delivered to the load individually and simultaneously [16]. The converter is able to accommodate voltage variations of the sources by using the current-fed $\mathrm{H}$-bridge converters. However, the topology is not able to maintain a bidirectional power flow and the current stress of the switching devices is high [16]. A three-port 
converter was proposed in [26] to couple a fuel cell and a battery system and the topology was also recommended in [27] for application in an uninterruptible power supply (UPS). Using batteries along the renewable energy sources increases the energy management flexibility [27], [28]. However, many technical points need to be considered when using batteries as energy storage [29]. As another application, a three-port converter is introduced using two current-fed ports to interface several energy storage elements such as batteries and super capacitors [30]. As a recent application, the magnetically coupled multi-port converter is used in a hybrid energy system for a residential house [17], [19]. The proposed topology enables the system to operate based on the different control techniques and energy management scenarios [16].

The common technique of coupling converter ports to the multi-winding transformer is using H-bridge dcac converters to generate a high-frequency rectangular waveform from the input dc voltage as discussed in more detail in [16],[31],[32]. The power flow control then can be realized by applying leading or lagging phase shift between the generated waveforms. The topology is suitable for medium-power applications (a few kilowatts) and the main advantages are simultaneous bidirectional power transfer between any input to any output, possibility of soft-switched operation for all coupled H-bridges, galvanic isolation between the input and outputs, capability of matching different voltage levels using transformer turns ratio and centralized control [16]. However, there are some disadvantages such as large number of switching devices, limited soft-switched region when operating with wide input voltage ranges and complexity of transformer design [16],[17]. The problem of soft-switching range in the case of using variable dc sources as the input source can be reduced by applying duty cycle control to the generated waveforms or using current-fed H-bridge converters instead of simple H-bridges [33]. In [34], the authors studied some other bridge converters with possibility of using in the phase shift converters. To analyse the multi-port phase shift converters, the multi-port topology can be decomposed into the simple dual active bridge (DAB) converter topologies as is discussed in [6], [16],[35]. The DAB converter was proposed by Kheraluwala and Divan in [36] and more detailed analysis was provided in [37]. The topology has been widely studied in the literature and modified considerably over the last decade. The improvement in the switching conditions of the bridge converter is studied in [38], [39] and the problem of circulating reactive power and possible solutions have been studied [40], [41].

In this paper, a multi-port phase shift converter topology based on a multi-winding high-frequency transformer for integrating a PV system, a wind turbine generator and a battery is introduced to supply a set of grid-connected domestic loads. The system is designed to transfer the power from renewable energy sources to the battery, load and grid. However, the power can be supplied from the grid to the battery in reverse direction when is required which increases the systems flexibility compared to the other proposed multi-port converter topologies. The system operation principle is discussed in detail and the control technique is also studied. A numerical simulation of the proposed topology and control technique is carried out using PSIM software to show the validity of system operation and the proposed control techniques.

\section{TOPLOGY OF THE PROPOSED CONVERTER}

The topology of the proposed Multi-port converter is presented in Fig.1. As illustrated in the figure, the converter topology contains four H-bridge dc-ac converters linked to a multi-winding transformer at one side and to a dc source at the other side. Fig.2 shows the H-bridge converter topology in more details. The H-bridge converter in port one is connected to a PV generation system, port two to a wind turbine generator, port three to a battery and port four to a high-voltage dc bus followed by a single phase inverter. In this structure, the transformer core is used as a magnetic coupling bus to transfer the power between the converter ports in a magnetic form [20],[21]. The main advantage of the system that power ports having different operating voltages are easily matched by transformer turns ratios and also are electrically isolated and their relation is only in the magnetic form [16]. As presented in the figure by arrows on the magnetic core, the power flows mainly from PV system and wind turbine to the battery and inverter ports, however a bidirectional; power flow also can be realized between the battery and inverter port. The power flow in this system can be controlled by a phase shift technique as studied in detail in [16], [42]. The H-bridge converter in port four is connected to a high-voltage dc linked as the dc voltage is going to be changed to a single phase ac voltage by the single-phase inverter $(220 \mathrm{Vrms}, f=50 \mathrm{~Hz}$ ). The generated ac voltage then can be supplied to the domestic loads or transferred to the grid as parallel link. The power also can be supplied by the power to the battery when the inverter is operating as a rectifier if the system is designed to operate as an uninterruptable power supply (UPS).

To analyse the power flow in the system, the system can be simplified by using the cantilever model of the multi-winding transformer. The multi-port converter with $\mathrm{N}$-port system can be decomposed into $\mathrm{N}(\mathrm{N}-1) / 2$ two-port converter as illustrated in Fig.3 [15],[16].The dc sources and the H-bridge converters are combined and presented as voltage source with a rectangular high-frequency waveform for the sake of simplicity. The structure can be simplified further as presented in Fig.3 where all the parameters at the transformer windings in port two, three and four are referred to the winding in port one and the magnetizing inductance is neglected as it has no influence on the power flow. As can be seen, the resultant structure shows that the four port 


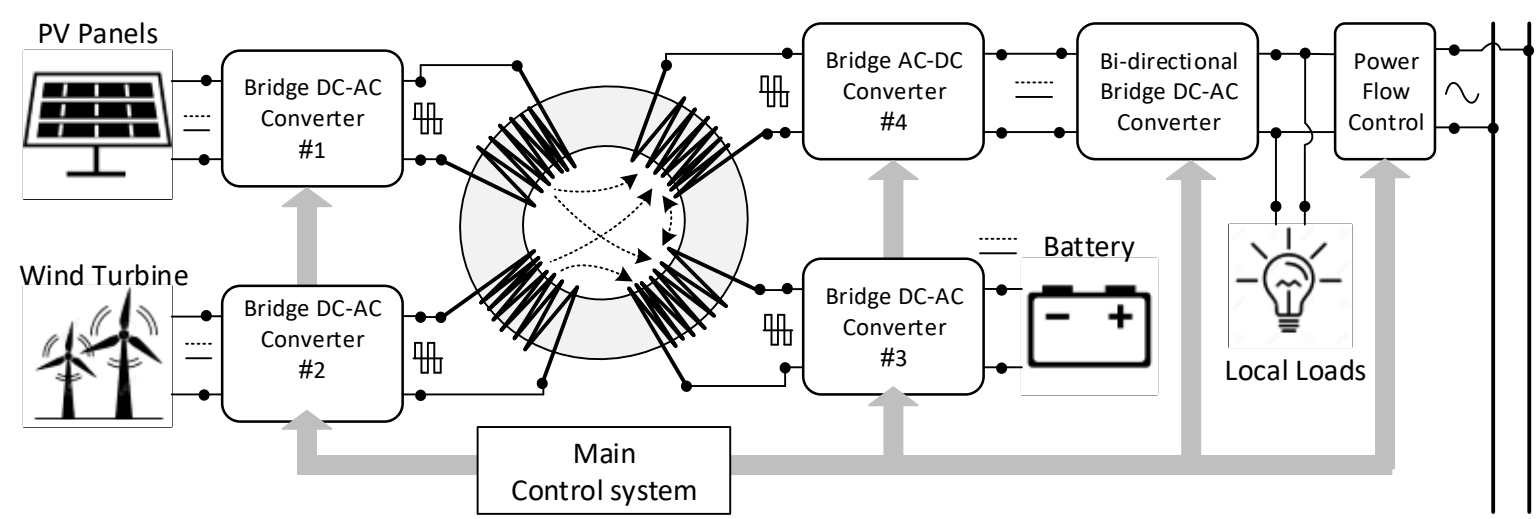

Figure 1. Topology of the proposed hybrid renewable energy system including the multi-port phase-shift converter and grid-connected inverter

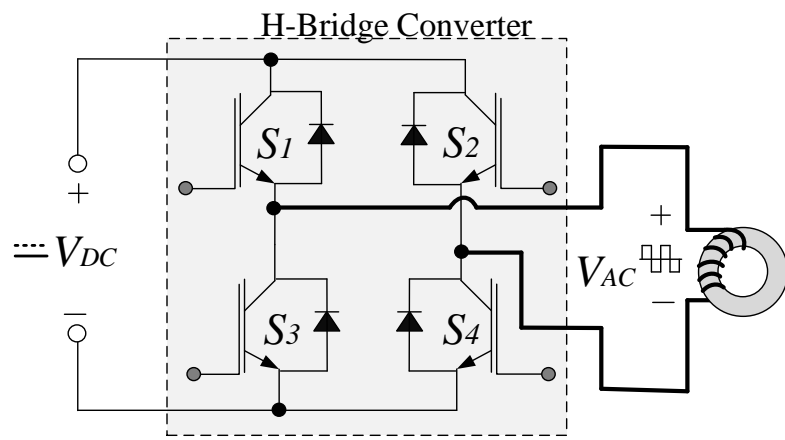

Figure 2. Topology of the H-bridge converter

converter topology can be decomposed in several dual active bridge converter. Therefore, the total power flows from each converter port can be obtained by summation of power flows to each individual port referring to simplified model in Fig.3. The power flow equations in the proposed converter according to the Fig. 3 can be written as

$$
\left\{\begin{array}{l}
P_{1}+P_{2}+P_{3}+P_{4}=0 \\
P_{1}=P_{12}+P_{13}+P_{14}, P_{2}=P_{21}+P_{23}+P_{24}, P_{3}=P_{31}+P_{32}+P_{34} \\
P_{i j}=-P_{j i} \text { for } i, j=1,2,3,4
\end{array}\right.
$$

To control the amount and direction of power flow, the generated rectangular waveforms are phase shifted from each other by controlled angles as presented in Fig.4 for the waveforms of the PV and inverter ports. The angles are named as $\delta_{14}$ to control the power flows from PV to the inverter port, $\delta_{24}$ from wind turbine to the inverter port, $\delta_{13}, \mathrm{PV}$ to the battery, $\delta_{23}$ from wind turbine to the battery port and $\delta_{34}$ for battery to the inverter port. The phase shift $\delta_{\mathrm{ij}}$ is positive when the voltage in port $i$ lags the reference voltage in port $j$ and negative when it leads the reference. The voltage of the inverter-linked winding is presented as $v_{4}$ does not have any duty cycle control and is selected as the reference due to its constant amplitude for convenience and the other generated waveforms have their duty cycles and phase shift angles defined with respect to $v_{4}$. The power flows from port $i$ to port $j$ presented as Pij when the waveform in port $i$ is one of the PV, battery and wind turbine ports are duty cycle controlled and $j$ represents the port four where the waveform's duty cycle is one can be determined as

$$
P_{i j}= \begin{cases}\frac{V_{i} V_{j}}{\omega L_{i j}} D \delta_{i j} & \left|\delta_{i j}\right| \leq \frac{\pi}{2}(1-D) \\ \frac{V_{i} V_{j}}{\omega L_{i j}}\left[\delta_{i j}\left(1-\delta_{i j} / \pi\right)-\operatorname{Sign}\left(\delta_{i j}\right) \frac{\pi}{4}(1-D)^{2}\right] & \frac{\pi}{2}(1-D)<\left|\delta_{i j}\right| \leq \frac{\pi}{2}\end{cases}
$$

where $V_{i}$ is the dc voltage in port $i, V_{j}$ the dc voltage in port $j, \omega$ the frequency of waveforms, $L_{i j}$ the summation of leakage inductance in windings $i$ and $j$ and $D$ duty cycle in the waveform of port $i$ as presented in Fig.4(a). On the other hand, the power flow between the two ports such as PV or wind turbine to the battery port where both waveforms have duty cycle controlled can be presented as 

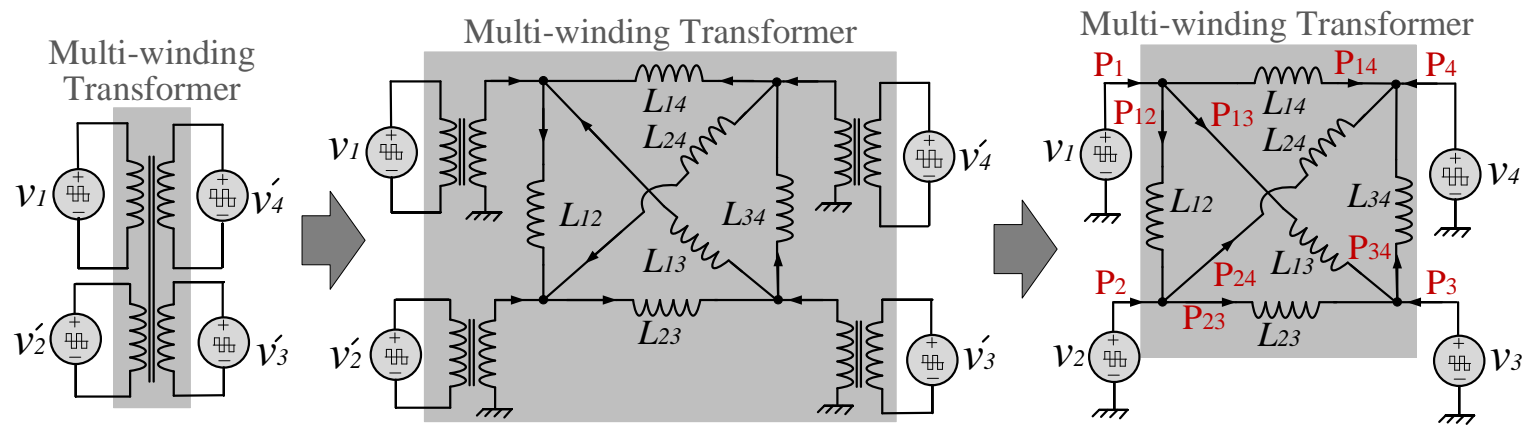

Figure 3. Simplified model of the four port converter by simplifying the multi-winding transformer using cantilever model

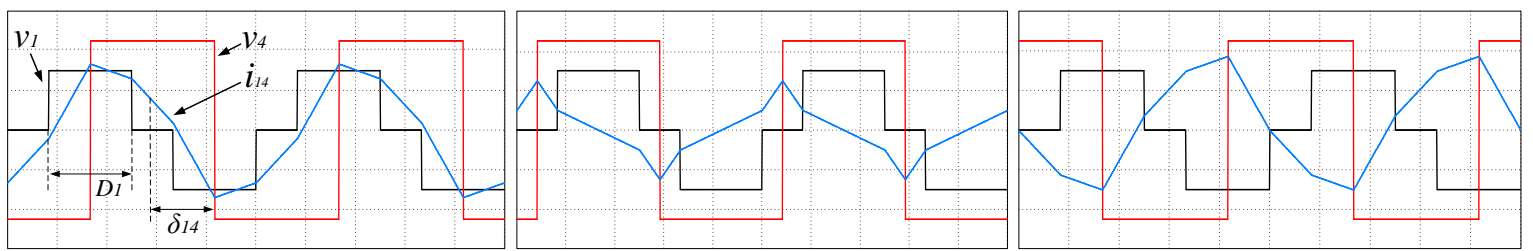

(a)

(b)

(c)

Figure 4. The waveforms of voltage and current of port one and four in the transformer winding for three cases of (a) $v_{l}$ is lagging $v_{4}$, (b) $v_{l}$ and $v_{2}$ are in phase and (c) $v_{l}$ is leading $v_{2}$ where duty cycle of $v_{l}\left(D_{l}\right)$ and phase shift angle are presented.

$$
P_{i j}= \begin{cases}\frac{V_{i} V_{j} D_{i} D_{j}}{\omega n L_{i j}\left(\max \left(D_{i}, D_{j}\right)\right)} \delta_{i j} & \left|\delta_{i j}\right| \leq \frac{\pi}{2}\left|D_{i}-D_{j}\right| \\ \frac{V_{i} V_{j} D_{j}}{\omega n L_{i j}}\left[\frac{\operatorname{Sign}\left(\delta_{i j}\right) \frac{\pi}{2}\left(D_{i}-D_{j}\right)+\delta_{i j}+}{D_{j}}\left[\operatorname{Sign}\left(\delta_{i j}\right)\left(-\frac{\pi}{4}\right)\left(D_{i}^{2}-D_{j}^{2}\right)+D_{i} \delta_{i j}-\operatorname{Sign}\left(\delta_{i j}\right) \frac{\delta_{i j}^{2}}{\pi}\right]\right] & \frac{\pi}{2}\left|\left(D_{i}-D_{j}\right)\right|<\left|\delta_{i j}\right| \leq \frac{\pi}{2}\left(2-D_{i}-D_{j}\right) \\ \frac{V_{i} V_{j}}{\omega n L_{i j}}\left[\delta_{i j}\left(1-\frac{\delta_{i j}}{\pi}\right)-\operatorname{Sign}\left(\delta_{i j}\right) \frac{\pi}{4}\left(1-D_{i}\right)^{2}-\operatorname{Sign}\left(\delta_{i j}\right)\left(1-D_{j}\right)^{2}\right] & \frac{\pi}{2}\left(2-D_{i}-D_{j}\right)<\left|\delta_{i j}\right| \leq \frac{\pi}{2}\end{cases}
$$

where $D_{i}$ and $D_{j}$ are the duty ratio of $v_{i}$ and $v_{j}$ and $v_{i} / D_{i}=v_{j} / n D_{j}$ and $n=N_{j} / N_{i}$. The waveforms frequency is kept constant and the leakage inductance of the transformer windings are utilised as the main energy transfer elements [16], [42]. A dc conversion ratio can be defined between the converter ports as

$$
d=\frac{V_{i}}{n V_{j}}
$$

where $n=N_{\mathrm{j}} / N_{\mathrm{i}}$ is the transformer turns ratio, $N i$ and $N j$ are the numbers of turns of the transformer windings in ports $i$ and $j$ respectively. Therefore, to analyse the four port converter, the DAB converter topology should be considered as a basic step. In this topology, a full range of soft switching operation is achievable when $d=$ 1 , which means an equal volt-second product of the voltage waveforms applied to the all transformer winding [24], [33]. In a lossless idealized circuit the maximum power flow between the ports can be determined from $\partial P_{i j} / \partial \delta_{i j}=0$ which results a maximum power at $P_{i j}=\pi / 2$. However, the phase shift angles greater than $\pi / 2$ results in an excessive reactive power and therefore, the phase-shift is practically limited to less than $\pi / 2$ [42].

\section{ANALYSIS OF CONTROL SYSTEM}

The power flow equations in (2), (3) show that the duty cycle and phase shift angle are the main elements that can be used as control variables. To discuss the control technique of the proposed converter, the simplified model of the phase shift converter facilitates the analysis. A main issue related to the PV and wind turbine generator as renewable energy sources is their inherent intermittency and uncertainty. Therefore, the generated electrical energy is variable and there is not a constant operation point to set the converter ports. As a result, the converter operating point in the PV and wind turbine ports needs to be adjusted according to the maximum available energy at any time. The process is known as maximum power point tracking (MPPT) in the PV and wind turbine converter ports. On the other hand, the extracted electrical power from the renewable energy 
sources should be controlled constantly and follows the load demand and the grid conditions and standards. In this paper, to realize the MPPT, the duty cycle of the switching devices in the H-bridge converters have been

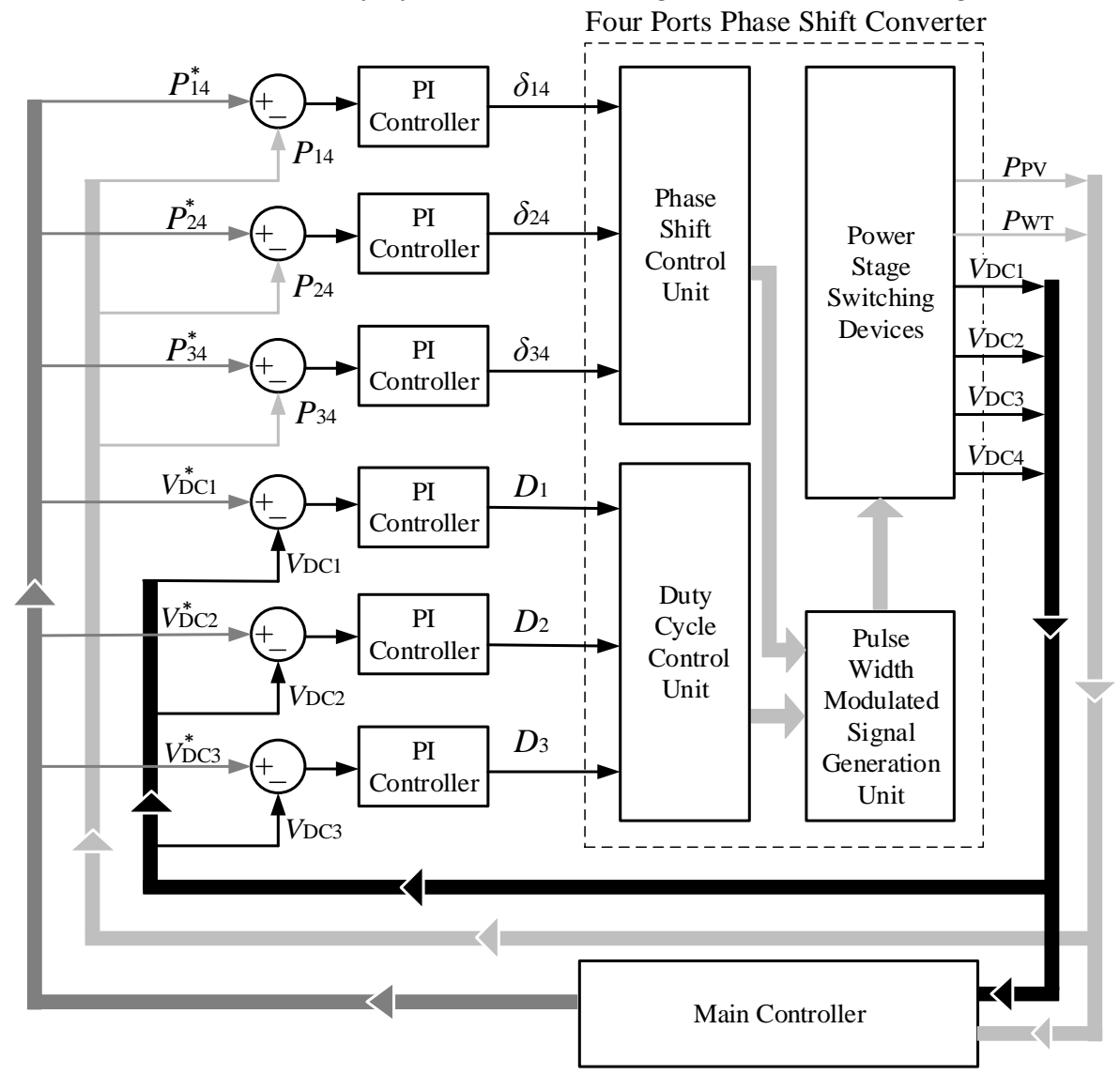

Figure 5. The control system for multi-port converter in the proposed system

used as control variable. On the other hand, the phase shift angle between the generated ac voltages at the converter ports is used to control the power flow between the converter ports. Therefore, the duty cycle control system should be designed to operate independent of the phase shift controller. In theory, arbitrary power flow in the system can be realized by a unique set of phase shifts [16]. In the system proposed in this paper, there are multiple control objectives. The power flow control scheme aims to control the power flow between the ports while regulating the dc bus voltage of the port. Fig. 5 illustrates the designed control system containing the control variables, reference signals provided by the master controller and the control loops. The proportional integral (PI) controllers have been used in the control loops to regulate the dc voltage and realize the MPPT operation. The PI controller transfer function is obtained as

$$
G_{C}(S)=K_{p}+\frac{K_{i}}{S}
$$

where $K_{p}$ and $K_{i}$ are the proportional and integral control coefficients and are set as 0.01 and 0.56 respectively. The power flow control in each converter port can be designed to regulate the voltage according to the provided reference signal. As voltage-type energy sources like wind turbine and PVs have a variable operating voltage, a power control strategy can be used as an equivalent of current control due to the slow change of the operating voltage of the source compared to the control bandwidth [16] and the dynamics of the power control loop is mainly determined by the port current. Therefore, the dynamics of the voltage control loop can be ignored in the control design process and it is regarded relatively constant value and as a gain in the control loop. Following this strategy, the dc extracted power from each of the renewable sources is controlled by using phase shift as the control variable. On the other hand, the power flow between the ports can be controlled by a proper selection of the phase shifts of the high-frequency voltages linked to the transformer windings. To reduce the control conflicts between the two variables (duty cycle and the phase shift), the dynamic response of the power flow control loop is designed to operate faster than the voltage control loop by designing proper controllers and adjusting $k_{p}$ and $k_{i}$. On the other hand, to reduce the conflict between the control loops in different converter ports, the dynamic response of the power control loops have been designed to operate in different speeds according to the nature and characteristics of the connected source as presented in Fig.6. As can be seen the 
crossing frequency of wind turbine control loop is about $200 \mathrm{~Hz}$ as the slowest source and the battery as 30 $\mathrm{kHz}$ as the fastest source. The duty cycle control loops have crossing frequencies less than $200 \mathrm{~Hz}$ for all three

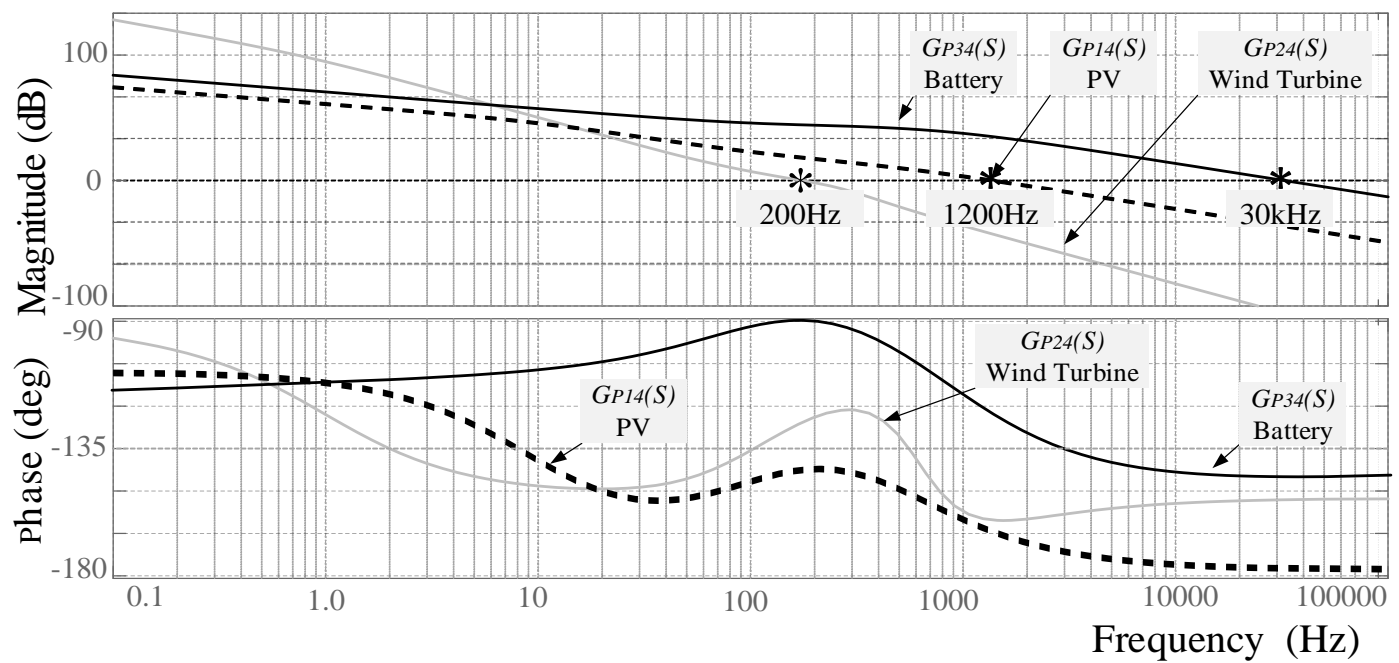

Figure 6. The magnitude and phase Bode diagrams of the power control closed loop transfer functions

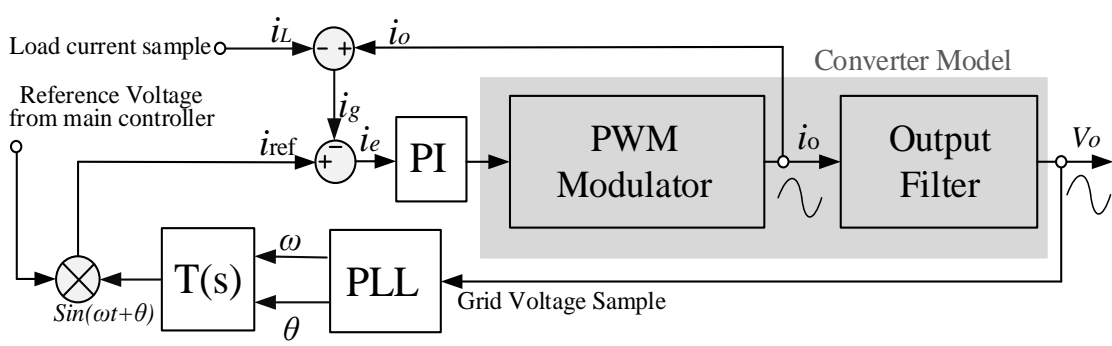

(a)

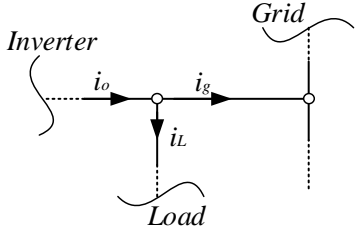

(b)

Figure 7. (a) The control system for the grid-connected inverter and (b) current direction reference in the inverter output

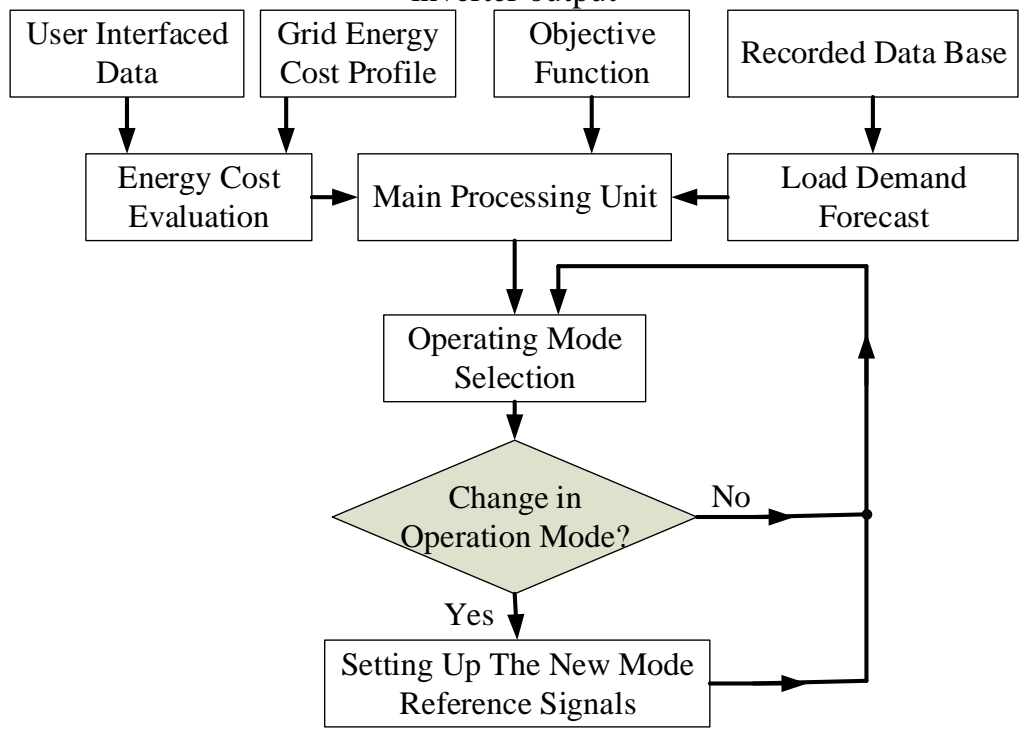

Figure 8. Energy management block diagram in brief

converter ports. At the inverter side, a current control technique is used to force a unity power factor injected or received from the grid. Fig.7 (a) shows the current control system designed for the grid-connected inverter. By using this control system, the inverter output current compensates the leading or lagging current of the load (reactive element of the load power) to have a unity power factor at the grid connected point. This is possible as referring to the current reference presented in Fig.7 (b) which shows that the grid current is basically depends 
on the load and inverter currents $\left(i_{g}=i_{o}-i_{L}\right)$. The energy management in the system uses the recorded data from previous operation times, real-time value of system parameters including voltage and current and energy cost as the main factors to determine the best operation scenario for the system as illustrated in Fig.8 in brief. So the operation scenarios and power flow directions in each scenario are selected to satisfy the objective function

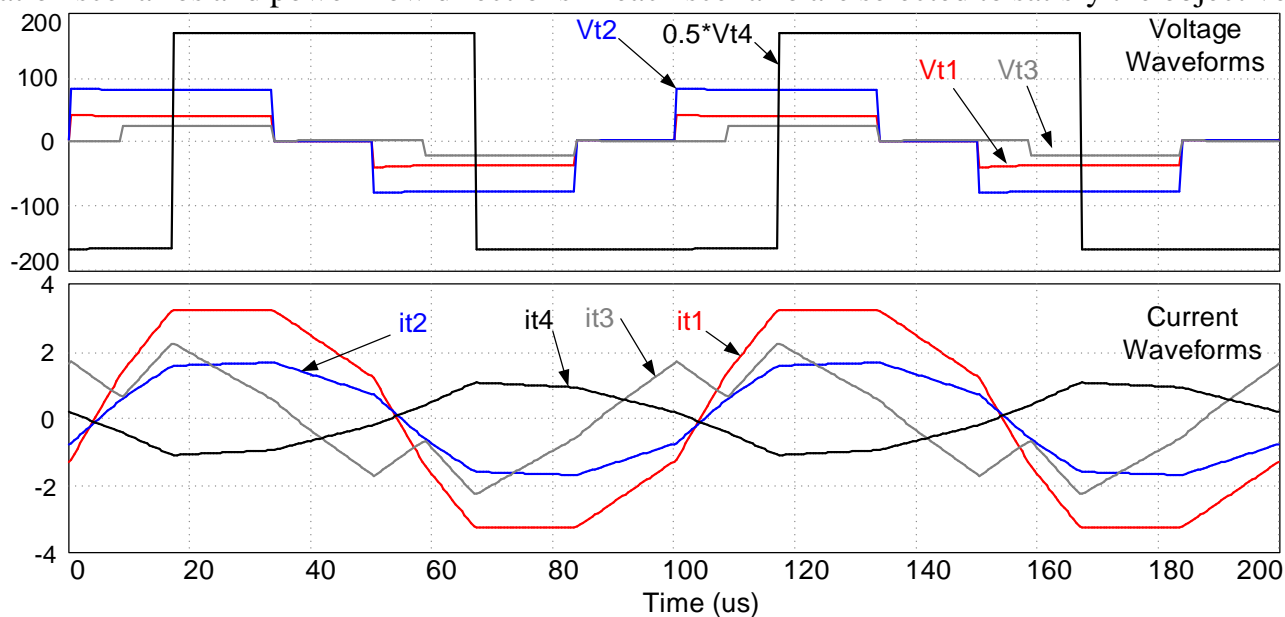

(a)
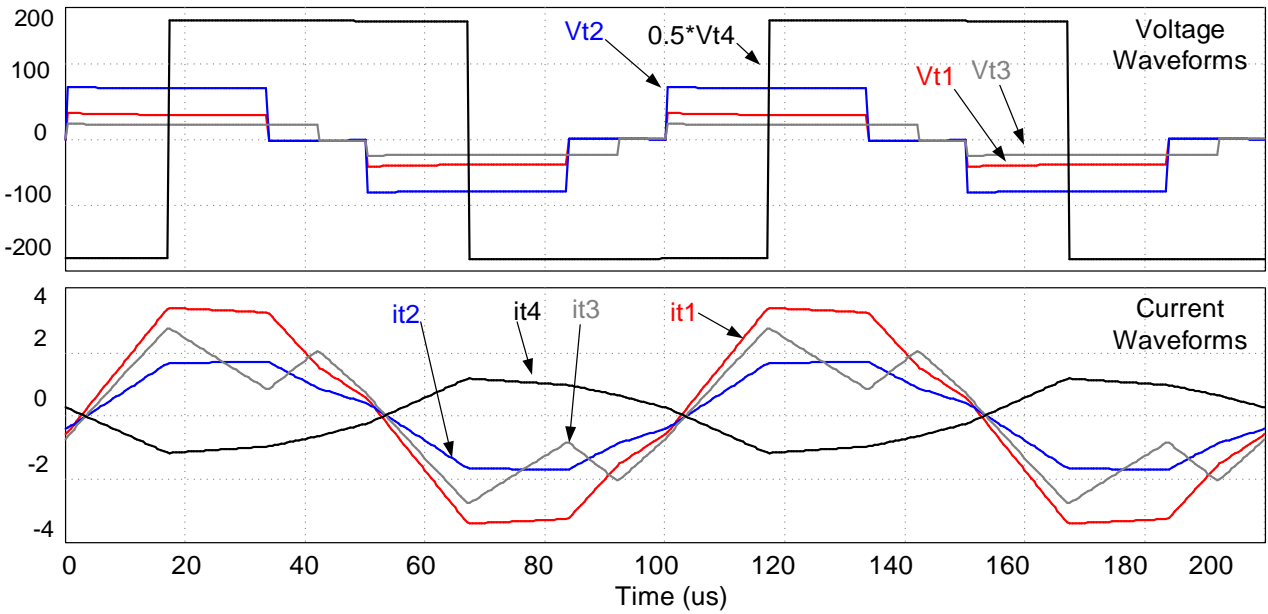

(b)

Figure 9. The waveforms of the voltage and current in the multi-winding transformer (a) for $\delta_{14}=\pi / 2, \delta_{24}=$ $\pi / 2, \delta_{34}=\pi / 2, D_{1}=0.6, D_{2}=0.6, D_{3}=0.4, \delta_{14}=\pi / 2$ and (b) $\delta_{14}=\pi / 2, \delta_{24}=\pi / 2, \delta_{34}=\pi / 2, D_{1}=0.6, D_{2}=0.6$,

$D_{3}=0.8$.

in the best way. Details of the energy management is out of scope of this paper and will be covered in the future reports.

\section{NUMERICAL SIMULATIONS}

The proposed system has been simulated using PSIM and the proposed control technique is implemented to control the power flow between the ports. The system can operate in different operation modes and the power can flow between the converter ports in different ways. A proper selection of the operation modes during a time frame is known as energy management scenario and different energy management scenarios considering various effective factors have been presented in the literature [17], [25]. This paper is mainly focused on the operation principle and control technique of the proposed system and energy management discussions is out of scope of this paper and will be presented in detail in the future publications. To provide a better understanding of the converter operation, some of the simulated waveforms of voltages and currents in the converter and grid-connected inverter have been presented and studied in this section. The system parameters have been selected in the numerical simulation are illustrated in Table.1.

The waveforms of the voltage and current of each converter port have been presented in Fig.9 (a) for two different cases of the phase shift angles and duty cycles. As can be seen the high-frequency voltage generated in the inverter port is not duty cycle controlled but the waveforms in the PV $\left(\mathrm{V}_{\mathrm{t} 1}\right)$, wind turbine $\left(\mathrm{V}_{\mathrm{t} 2}\right)$ and the battery $\left(\mathrm{V}_{\mathrm{t} 3}\right)$ ports are duty cycle controlled. The power is transferred from $\mathrm{PV}$, wind turbine and the battery to 
the inverter port. The currents in the windings of the transformer have also been presented. In the second case the power flows from PV and wind turbine ports to the battery and inverter ports at the same time. As can be seen the voltage in the PV and wind turbine ports is leading compared to that of battery and inverter. The duty cycle of voltage in the battery port is different compared to the previous case.

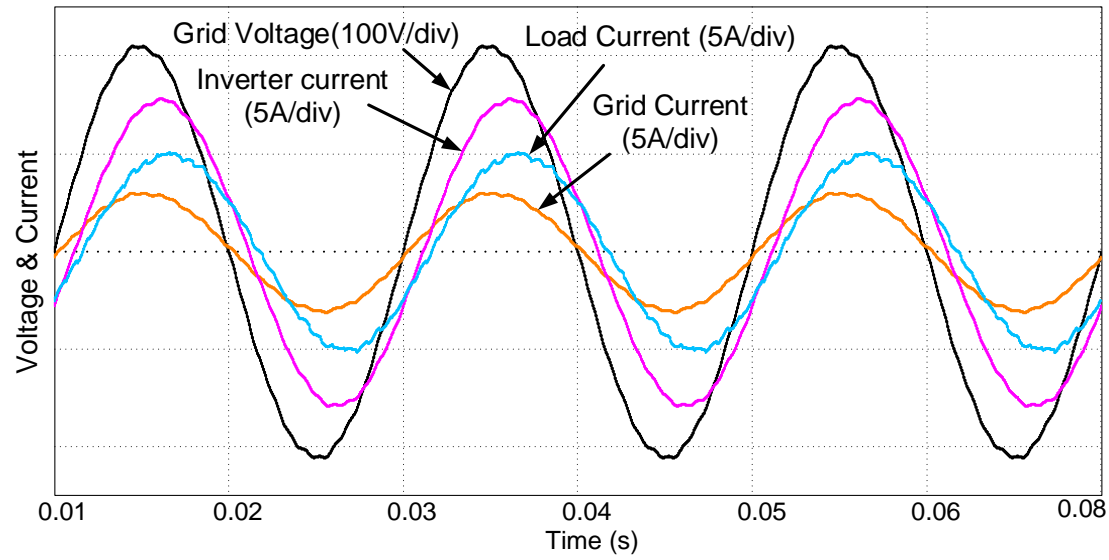

(a)

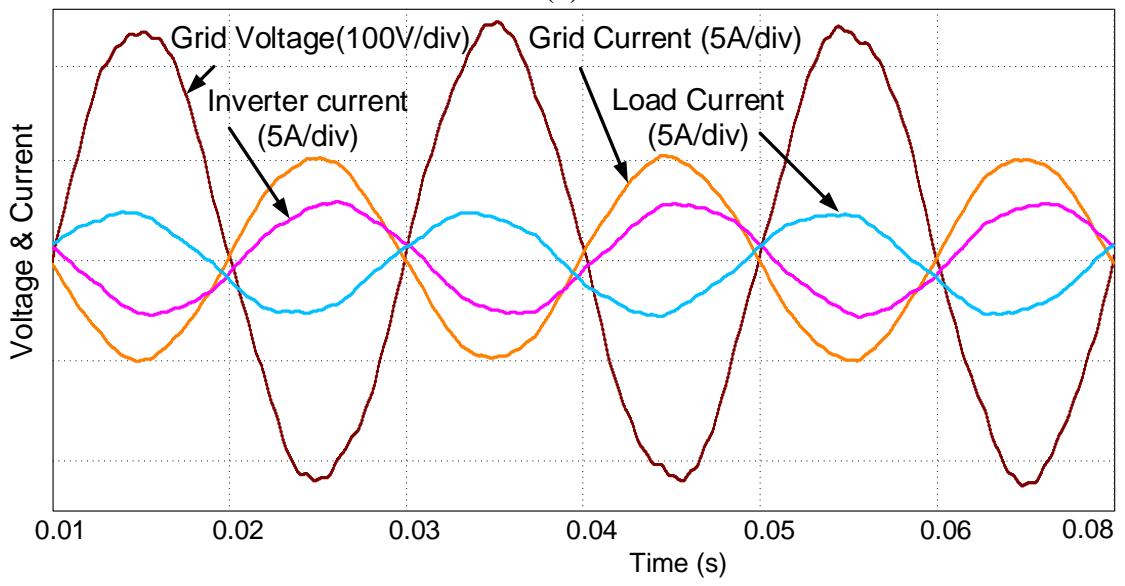

(b)

Figure 10. The inverter output, load and the grid currents (a) when power is transferred from the inverter to the grid and the load and, (b) when inverter is operating as rectifier and power is transferred in posit direction from grid to the load and battery reduced back to the previous value.

Table.1 System parameters for numerical simulations

\begin{tabular}{|c|c|c|c|}
\hline Parameters & Values & Parameters & Values \\
\hline $\begin{array}{l}\text { Number of turns of each winding } \\
\text { of the transformer }\end{array}$ & $\mathrm{N}_{1}=7, \mathrm{~N}_{2}=6, \mathrm{~N}_{3}=5, \mathrm{~N}_{4}=18$ & DC bus voltage & $\begin{array}{l}\mathrm{V} 1=110 \mathrm{~V}, \mathrm{~V} 2=100 \\
\mathrm{~V}, \mathrm{~V} 3=80 \mathrm{~V}, \mathrm{~V} 4=300 \\
\mathrm{~V},\end{array}$ \\
\hline Magnetising inductance $\mathrm{L}_{\mathrm{m}}$ & $\mathrm{L}_{\mathrm{m}}=1.12 \mathrm{mH}$ & $\begin{array}{l}\text { Switching frequency of } \\
\text { Inverter }\end{array}$ & $\mathrm{f}_{\mathrm{si}}=10 \mathrm{kHz}$ \\
\hline $\begin{array}{l}\text { PV characteristics (Totally } 6 \\
\text { Panels connected in two } \\
\text { paralleled branches) }\end{array}$ & $\begin{array}{l}\text { Each panel: } V o=35 \mathrm{~V}, \mathrm{I}_{\max }=6 \mathrm{~A} \\
\mathrm{P}_{\max }=200 \mathrm{~W}\end{array}$ & $\begin{array}{l}\text { Wind turbine } \\
\text { characteristics }\end{array}$ & $\begin{array}{l}\mathrm{V}=100 \mathrm{~V} \mathrm{dc}, \mathrm{P}=800 \\
\mathrm{~W} \\
\mathrm{I}_{\max }=9 \mathrm{~A}\end{array}$ \\
\hline
\end{tabular}

Fig.10 shows the inverter output waveform. The main objective for the inverter is to supply the load and possibly the grid from renewable energy sources or transfer the energy in reverse direction form the grid to the battery to charge the battery when is required. However, any energy transfer to/from the grid should be under the unity power factor as the main condition for the grid-connected residential renewable energy systems. Therefore, the inverter output is controlled to provide the required output current with a proper phase shift angle to satisfy the mandatory conditions. This was already discussed in the controller design section. As can be seen in Fig.10 (a), inverter is supplying the load and the grid. As the load current is slightly lagging the

A Grid-connected Hybrid Renewable Energy System Using High-frequency... (Ramesh Kumar et al) 


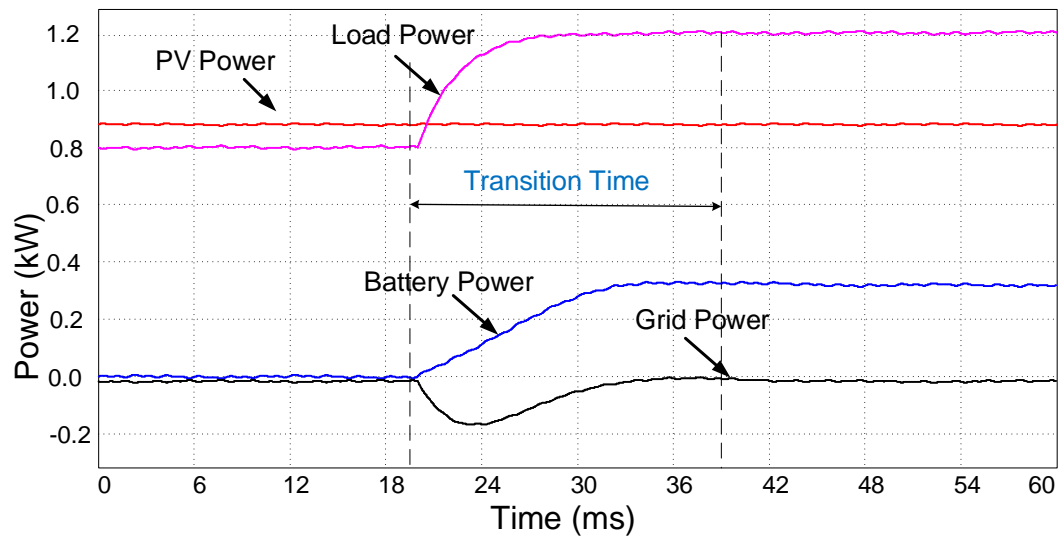

(a)

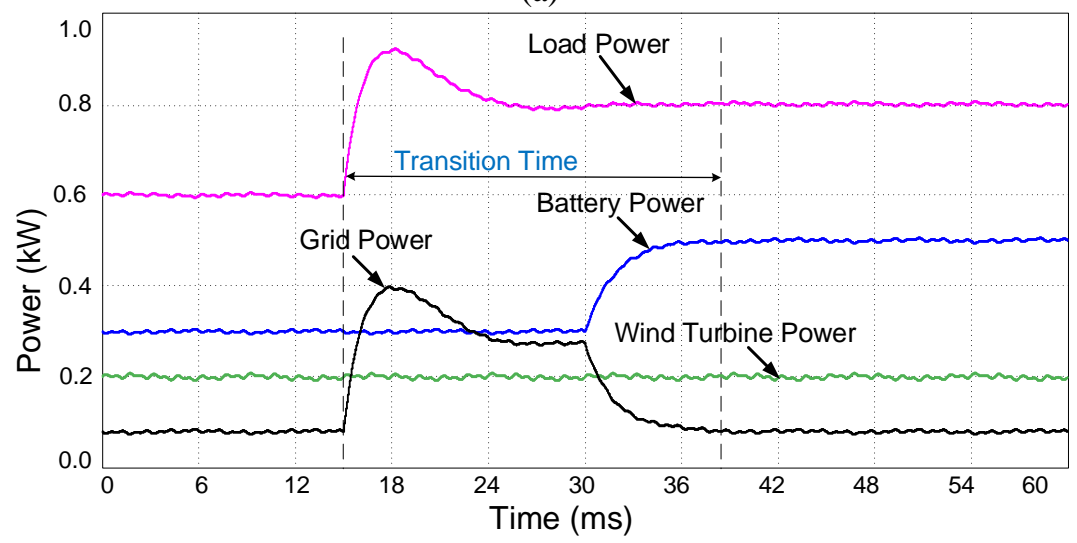

(b)

Figure 11. Step response in the load demand and operation of proposed system in compensation of load demand (a) when the load demand is compensated by the battery during transition time, and (b) when the load demand is compensated by the utility grid during the transition time.

voltage, the inverter output is compensating the difference to force the grid current toward a unity power factor as $i_{g}=i_{o}-i_{L}$ considering $i_{o}$ as the inverter output current, $i_{L}$ as the load current and $i_{g}$ as the injected current into the utility grid. In the second case as presented in Fig.10 (b), the power flows in opposite direction from the grid to the load and inverter (charging the battery). In this case the inverter is operating as a rectifier in reverse direction and the received current adjusted properly to compensate for the slight phase shift in the load current due to the inductive load effect.

To study the dynamic response of the power flow control, two different cases of power flow control have been presented in Fig.11. As can be seen, in the first case, the response of the system to a step changes in the load while the output power extracted from PV and the wind turbine is almost constant. The difference between the load demand and the renewable power is compensated by the battery. However, it can also be supplied by the utility grid depending on the availability of the battery energy and the cost of the grid energy compared to the battery at the presented time. The load demand variation is simulated by adding/removing a resistor in parallel with the output filter capacitor. In the second case, the load is supplied by the battery, grid and the wind turbine. When the load demand is increased, the demand is covered by the grid at the first stage. However, after a transient time the battery port is activated to undertake the demand supply and therefore, the grid power is reduced to the previous value. The command for changing operation condition is normally provided by the main control energy management section and the detail of energy management will be provided in the future publications.

\section{CONCLUSIONS}

A multiport converter topology for integrating a PV system, a wind-turbine generator and a battery is presented in the paper to supply a grid-connected domestic load. The operation principle and control technique of the proposed system presented in detail. To validate the system topology and control technique, numerical simulations have been performed using PSIM software. The waveforms of the voltage and currents of the 
multi-port converter and inverter and the dynamic response of the system under a step change in the load have been presented and analysed.

\section{REFERENCES}

[1] H. Tao, J. L. Duarte and M. A. M. Hendrix, "Three-Port Triple-Half-Bridge Bidirectional Converter With Zero-Voltage Switching," IEEE Trans. Power Electro., vol. 23, no. 2, pp. 782-792, March 2008.

[2]-M. Jafari, Z. Malekjamshidi and J. Zhu, "Design, analysis and control of a magnetically-coupled multi-port multioperation-mode residential micro-grid," 2017 20th International Conference on Electrical Machines and Systems (ICEMS), Sydney, NSW, 2017, pp. 1-6.

[3] C. Zhao, S. Round, and J. W. Kolar, "Buck and boost start-up operation of a three-port power supply for hybrid vehicle applications,” in Proc. IEEE Power Electronics Specialists Conference (PESC'05), Recife, Brazil, Jun. 2005, pp. 1851-1857.

[4]-Z. Malekjamshidi, M. Jafari and M. Imanieh, "Implementation of a Full Bridge Series-Parallel Resonant DC-DC converter using ANN and SSM controllers," Proceedings of the 2011 IEEE National Aerospace and Electronics Conference (NAECON), Dayton, OH, 2011, pp. 203-210.

[5]-M. Jafari, Z. Malekjamshidi and Jian Guo Zhu, "Design, simulation and implementation of an intelligent MPPT using a ZVCS resonant DCDC converter," 2012 IEEE International Conference on Power and Energy (PECon), Kota Kinabalu, 2012, pp. 280-285.

[6] J. L. Duarte, M. Hendrix, and M. G. Simoes, "Three-port bidirectional converter for hybrid fuel cell systems," IEEE Trans. Power Electron., vol. 22, no. 2, pp. 480-487, Mar. 2007.

[7] Y. M. Chen, Y. C. Liu, and F. Y. Wu, "Multi-input DC/DC converter based on the multiwinding transformer for renewable energy applications," IEEE Trans. Ind. Appl., vol. 38, no. 4, pp. 1096-1104, Jul./Aug. 2002.

[8] Z. Malekjamshidi, M. Jafari, M. R. Islam and J. Zhu, "A comparative study on characteristics of major topologies of voltage source multilevel inverters," 2014 IEEE Innovative Smart Grid Technologies - Asia (ISGT ASIA), Kuala Lumpur, 2014, pp. 612-617.

[9] H.Tao, A. Kotsopoulos, J. L. Duarte, and M. A. M. Hendrix, "Family of multiport bidirectional DC-DC converters," IEE Proceeding Electric Power Applications, vol. 153, no. 3, pp. 451-458, May 2006.

[10] Y. C. Liu and Y. M. Chen, "A systematic approach to synthesizing multiple-input dc-dc converter," IEEE Trans. Power Electron., vol. 24, no. 1, pp. 116-127, Jan. 2007.

[11] N. D. Benavides and P. L. Chapman, "Power budgeting of a multiple-input buck-boost converter, "IEEE Trans. Power Electron., vol. 20, no. 6, pp.1303-1309, Nov. 2005.

[12] B. G. Dobbs and P. L. Chapman, “A multiple-input DC-DC converter topology," IEEE Power Electronics Letters, vol. 1, no. 1, pp. 6-9, Mar. 2003.

[13]- M. Jafari, G. Hunter and Jian Guo Zhu, "A new topology of multi-input multi-output Buck-Boost DC-DC Converter for microgrid applications," 2012 IEEE International Conference on Power and Energy (PECon), Kota Kinabalu, 2012, pp. 286-291.

[14] J. L. Duarte, M. Hendrix, and M. G. Simoes, “Three-port bidirectional converter for hybrid fuel cell systems, "IEEE Trans. Power Electron., vol. 22, no. 2, pp. 480-487, Mar. 2007.

[15] H. Tao, A. Kotsopoulos, J. L. Duarte, and M. A. M. Hendrix, "Family of multiport bidirectional DC-DC converters, " IEE Proceeding Electric Power Applications, vol. 153, no. 3, pp. 451-458, May 2006.

[16] H.Tao, "Integration of sustainable energy sources through power electronic converters in small distributed electricity generation systems", Phd thesis, Eindhoven :Technische Universiteit Eindhoven, 2008.

[17] Jafari, M, Malekjamshidi, Z \& Zhu, J 2019, 'A magnetically coupled multi-port, multi-operation-mode micro-grid with a predictive dynamic programming-based energy management for residential applications', International Journal of Electrical Power \& Energy Systems, vol. 104, no. January 2019, pp. 784-796.

[18] M. Jafari, Z. Malekjamshidi, M. R. Islam and J. Zhu, "Modeling of magnetic flux in multi-winding toroidal core high frequency transformers using 3D reluctance network model," 2015 IEEE 11th International Conference on Power Electronics and Drive Systems, Sydney, NSW, 2015, pp. 413-418.

[19] M. Jafari, Z. Malekjamshidi, J. Zhu and M. Khooban, "Novel Predictive Fuzzy Logic-Based Energy Management System for Grid-connected and Off-grid Operation of Residential Smart Micro-grids," IEEE Journal of Emerging and Selected Topics in Power Electronics.

[20] H. Tao, A. Kotsopoulos, J. L. Duarte and M. A. M. Hendrix, "Transformer-Coupled Multiport ZVS Bidirectional DCDC Converter With Wide Input Range," IEEE Trans.Power Electron., vol. 23, no. 2, pp. 771-781, March 2008.

[21]- M. Jafari, Z. Malekjamshidi and J. Zhu, "Copper Loss Analysis of a Multiwinding High-Frequency Transformer for a Magnetically-Coupled Residential Microgrid,"IEEE Trans. Ind. Applications, vol. 55, no. 1, pp. 283-297, Jan.-Feb. 2019.

[22]- E. L. Barrios, A. Ursúa, L. Marroyo and P. Sanchis, "Analytical Design Methodology for Litz-Wired High-Frequency Power Transformers," IEEE Trans. Ind. Electron., vol. 62, no. 4, pp. 2103-2113, April 2015

[23]-M. Jafari, Z. Malekjamshidi, G. Lei, T. Wang, G. Platt and J. Zhu, "Design and Implementation of an Amorphous High-Frequency Transformer Coupling Multiple Converters in a Smart Microgrid," IEEE Trans.Industrial Electronics, vol. 64, no. 2, pp. 1028-1037, Feb. 2017. 
[24]-Jafari, M, Malekjamshidi, Z \& Zhu, J 2019, 'Design and development of a multi-winding high-frequency magnetic link for grid integration of residential renewable energy systems', Applied Energy, vol. 242, pp. 1209-1225.

[25] Y. M. Chen, Y. C. Liu, and F. Y. Wu, "Multi-input DC/DC converter based on the multiwinding transformer for renewable energy applications,” IEEE Trans. Ind. Appl., vol. 38, no. 4, pp. 1096-1104, Jul./Aug. 2002.

[26] M. Michon, J. L. Duarte, M. Hendrix, and M. G. Simoes, "A three-port bi-directional converter for hybrid fuel cell systems,” IEEE Power Electronics Specialists Conference (PESC'04), Aachen, Germany, Jun. 2004,pp. 4736-4742.

[27] C. Zhao and J. W. Kolar, "A novel three-phase three-port UPS employing a single high-frequency isolation transformer," IEEE Power Electronics Specialists Conference (PESC'04), Aachen, Germany, Jun. 2004, pp.41354141.

[28] M. Jafari, Z. Malekjamshidi, D. D. Lu and J. Zhu, "Development of a Fuzzy-Logic-Based Energy Management System for a Multiport Multioperation Mode Residential Smart Microgrid," IEEE Trans. Power Electron., vol. 34, no. 4, pp. 3283-3301, April 2019.

[29] M. Jafari, G. Platt, Z. Malekjamshidi and J. G. Zhu, "Technical issues of sizing Lead-Acid batteries for application in residential renewable energy systems," 2015 4th International Conference on Electric Power and Energy Conversion Systems (EPECS), Sharjah, 2015, pp. 1-6.

[30] D. Liu and H. Li, “A ZVS bi-directional DC-DC converter for multiple energy storage elements," IEEE Trans. Power Electron., vol. 21, no. 5, pp. 1513-1517, Sep. 2006

[31] M. Jafari, Z. Malekjamshidi, Li Li and Jian Guo Zhu, "Performance analysis of full bridge, boost half bridge and half bridge topologies for application in phase shift converters," 2013 International Conference on Electrical Machines and Systems (ICEMS), Busan, 2013, pp. 1589-1595.

[32] M. Jafari, Z. Malekjamshidi, G. Platt, J. G. Zhu and D. G. Dorrell, "A multi-port converter based renewable energy system for residential consumers of smart grid," IECON 2015 - 41st Annual Conference of the IEEE Industrial Electronics Society, Yokohama, 2015, pp. 005168-005173.

[33] Y. Shi, R. Li, Y. Xue, and H. Li, "High-frequency-link-based grid-tied PV system with small DC-link capacitor and low-frequency ripple-free maximum power point tracking," IEEE Trans. Power Electron. vol. 31, no. 1, pp. 328 339, Jan. 2016.

[34] G. Chen, D. Xu, Y. Wang, and Y. Lee, "A new family of soft-switching phase-shift idirectional DC-DC converters," IEEE Power Electronics Specialists Conference (PESC'01), Jun. 2001, pp. 859-865.

[35] M. Jafari, M. R. Islam, Z. Malekjamshidi and Jianguo Zhu, "Modeling of multi-winding high-frequency transformers as a common magnetic-link in smart micro-grids," 2015 International Conference on Electrical \& Electronic Engineering (ICEEE), Rajshahi, 2015, pp. 249-252.

[36] M. H. Kheraluwala, R. W. Gascoigne, D. M. Divan, and E. D. Baumann, "Performance characterization of a highpower dual active bridge DC-to-DC converter," IEEE Trans. Ind. Appl., vol. 28, no. 6, pp. 1294-1301, Nov./Dec.1992.

[37] K. Vangen, T. Melaa, S. Bergsmark, and R. Nilsen, "Efficient high-frequency soft-switched power converter with signal processor control," IEEE Telecommunications Energy Conference (INTELEC'91), Nov. 1991, pp. 631-639.

[38] K. Vangen, T. Melaa, and A. K. Adnanes, "Soft-switched high-frequency, high power DC/AC converter with IGBT, ” IEEE Power Electronics Specialists Conference (PESC'92), Jun. 1992, pp. 26-33.

[39] K. Vangen, T. Melaa, A. K. Adnanes, and P. E. Kristiansen, "Dual active bridge converter with large soft-switching range," Fifth European Conference on Power Electronics and Applications (EPE'93), Sep. 1993, pp. 328-333.

[40] J. M. Zhang, D. M. Xu, and Z. Qian, “An improved dual active bridge DC/DC converter,"IEEE Power Electronics Specialists Conference (PESC'01), Vancouver, BC, Canada, Jun. 2001, pp. 232-236.

[41] J. Zhang, F. Zhang, X. Xie, D. Jiao, and Z. Qian, “A novel ZVS DC/DC converter for high power applications," IEEE Trans. Power Electron., vol. 19, no. 2, pp. 420-429, Mar. 2004.

[42] M. Jafari, Z. Malekjamshidi and J. G. Zhu, "Analysis of operation modes and limitations of dual active bridge phase shift converter," 2015 IEEE 11th International Conference on Power Electronics and Drive Systems, Sydney, NSW, 2015, pp. 393-398. 